\title{
PHILOSOPHY
}

\section{ЭТИЧЕСКИЕ ПОСТУЛАТЫ АСПЕКТОВ БИОЭТИКИ В РАКУРСЕ МЕДИКО-БИОЛОГИЧЕСКИХ ИССЛЕДОВАНИЙ}

\author{
Др. ф. Гамар Ханум Джавадлы \\ Управление Мусульман Кавказа, Баку, Азербайджсан \\ ORCID 0000-0001-6229-2860
}

\section{DOI: https://doi.org/10.31435/rsglobal_ws/30122019/6836}

\begin{abstract}
ARTICLE INFO
Received: 24 October 2019

Accepted: 20 December 2019

Published: 30 December 2019

KEYWORDS

bioethics,

biomedicine,

moral standards,

ethical principles,

human values.

ABSTRACT

Bioethics is the new starting point of philosophical thought. Its formation and development is directly related to the transformation of medical ethics as a whole. A traditional methodological tool for acquainting oneself with the scientific, socio-political and moral essence of bioethics in the modern world is an excursion into the history of the origin and stages of the development of the subject. Interest in bioethics is, first of all, an indicator of global public attention to human rights, the use of new technologies and medical experiments on people, which in turn create serious legal and moral problems in society. Today, there is a need to study theoretical and historical aspects in order to study and classify this issue. The article discusses and sets out in detail the foundations of an ethical attitude to the human person from the perspective of biomedicine.
\end{abstract}

Citation: Gamar Khanim Javadli. (2019) Ethical Postulates of Bioethics Aspects from the Perspective of Biomedical Research. World Science. 12(52), Vol.2. doi: 10.31435/rsglobal_ws/30122019/6836

Copyright: (C) 2019 Gamar Khanim Javadli. This is an open-access article distributed under the terms of the Creative Commons Attribution License (CC BY). The use, distribution or reproduction in other forums is permitted, provided the original author(s) or licensor are credited and that the original publication in this journal is cited, in accordance with accepted academic practice. No use, distribution or reproduction is permitted which does not comply with these terms.

Введение. Одной из главных причин происхождения биоэтики ученые считают моральнодуховные или деонтологические проблемы, возникающие во время профессиональной деятельности врачей и вызывающие частые разногласия в обществе. В достаточно сложное и конфронтационное политическое, экономическое, культурное время такие сложные взаимоотношения как человек - человек, человек - природа, человек - окружающая среда, человек - культура, мораль, право и т.д. вырываются из контекста индивидуального сознания и поднимаются до национального и общественного уровня самопознания. Упомянутые реальные факторы и условия обусловили возникновение нового обобщенного восприятия и синтеза научных предметов. Биоэтика, как околонаучная дисциплина и новая интегрирующая научно-практическая область, именно по этой причине нашло свое утверждение начиная середины XX века.

Традиционным методологическим средством для ознакомления с научно-общественнополитической и моральной сущностью биоэтики в современном мире является экскурс в историю возникновения и этапы развития предмета. Невозможно не учитывать влияние различных научных факторов и философских категорий на формирование биоэтики. Некоторые исторические факторы имеют особое значение: например, период эволюции между Клятвой Гиппократа и Нюрнбергским процессом сыграл благоприятную роль для превращения биоэтики в феномен общественной мысли.

Биоэтика является новым исходным пунктом философской мысли. Ее формирование и развитие напрямую связано с трансформацией медицинской этики в целом. Интерес к биоэтике, прежде всего, показатель глобального общественного внимания к правам человека, использования 
новых технологий и медицинских опытов над людьми, которые в свою очередь создают серьезные правовые и моральные проблемы в обществе. Сегодня существует необходимость изучения теоретических и исторических аспектов для исследования и классификации данной проблематики.

Термин «биоэтика» предложен В.Р. Поттером в 1969 году. По определению Оксфордского словаря 1989 г. биоэтика - это «дисциплина, имеющая дело с этическими проблемами, возникающими в результате прогресса медицины и биологии». Следовательно, если традиционная медицинская этика имеет дело только с общечеловеческими понятиями, возникающими во взаимоотношениях врача и пациента, то биоэтика распространяет их на генетику и поведение людей, на социальные аспекты здравоохранения, этику демографического контроля, эксперименты на животных и людях, проблему окружающей среды и т.п. Действительно, это широкое поле совместных интересов философов, юристов, психологов, социологов, юристов и даже теологов, представляющих все ведущие религии мира. А ее конечная цель - защита человека и общества от возможных негативных воздействий и вообще сложностей, возникающих в связи с бурным прогрессом науки, с помощью таких инструментов как правила, нормы, законы или иные правовые документы. Биоэтика, таким образом, это исследовательское направление междисциплинарного характера.

\section{Биоэтика как вариант «новой этики»: причины появления, определение, специфика}

Сегодняшняя наука открывает новые горизонты в отношении к человеку. Вследствие массированного вторжения в медицину новых технологий, вдруг обнаружилось огромное количество необычных, сложных, противоречивых проблем, многие из которых не имеют однозначного решения. Проблемы эти отразились в столь же непривычных новых понятиях, нуждающихся в осмыслении. Появилось множество вопросов, порожденных практикой, требующих ответов. За последние десятилетия складывается фактически новая этика. Новые «этические стандарты», выходящие сегодня на уровень общественного сознания, такие понятия, как «моральность убийства», «моральность отключения жизнеподдерживающей аппаратуры» стали обычны для научной общественности, обсуждающей проблемы эвтаназии, которые в философско-этическом аспекте выходят за пределы классической этики [1;21].

Один из стандартов новой этики связан с реанимационной практикой. Совершенствование реанимационных методик (дыхательные аппараты, «искусственная почка» и др.) превратило умирание в длительный механизированный процесс, поставив принципиально новый для человека морально-этический вопрос: кто в данной ситуации должен принимать решение о смерти - сам умирающий, врачи или родственники? Действия, оцениваемые в традиционном моральном сознании как убийство или самоубийство, в новом технологическом пространстве медицины приобретают гуманный статус, определяемый новым морально-этическим принципом: «достойно жить, достойно умереть». Данная реальность в значительной степени понуждает к формированию у медицины, наряду с традиционно здравоохранительной, новой функции - смертеобеспечение. Эта функция прочно закрепляется развитием трансплантологии, ибо основным источником биоматериала - человеческих органов, подлежащих трансплантации, являются терминальные пациенты, («terminus» - конец), предел которых, продлеваемый во времени, должен быть специальным образом организован. Для формирования нового этического стандарта используется превращенная форма - «дарение своих органов». Именно он определяет и новые критерии гуманности, - чем выше «органическая ценность», тем выше гуманность, наличие которой проявляется в способности к «дарению своего биоматериала». Однако если этому праву еще предстоит завоевывать умы, то право на уничтожение своего биоматериала (аборт) уже обрело статус стандарта.

Вытеснение многих традиционных ценностей возможно и ожидаемо при условии неограниченного и массового распространения методик искусственного оплодотворения. Прогресс терапии бесплодия сделает нормой асексуальное размножение. Это вызовет деформацию биологических и физиологических связей, родственных и человеческих взаимоотношений, что приведет к разрушению одного из оснований нравственной культуры личности. В ближайшей перспективе под влиянием массового внедрения практик искусственного оплодотворения в разряд этических стандартов попадают не только неполные семьи, но и однополые браки, суррогатное материнство, которое можно смело назвать «биологической проституцией». Практика генетической диагностики приводит к вопросам: что такое здоровая наследственность, хороший или плохой ген; существует ли мера допустимых 
для общества аномалий? Как бы интересны эти вопросы ни были сами по себе, они в то же время могут превратиться в основание генетической политики.

Неудивительно, что генные технологии называют «новым социальным оружием». Неотступной тенью генетических исследований являются евгенические программы, понятийный арсенал которых - «коррекция естественного отбора», «генетическое наступление», «искусственный отбор». Правда, не определены еще ценностно-содержательные критерии. Но это лишь еще одна возможность коррекции старых, традиционных моральных ценностей и норм. Принцип «личного права» стал этическим стандартом и для «антипсихиатрического» движения. В его основе - признание права каждого человека на свой образ мира. Последовательное осуществление этического стандарта «личное право» оборачивается реальным обесцениванием традиционных норм. Приведенные варианты решения некоторых моральных проблем медицины представлены в абстрактно-гипотетическом пределе. Можно ли новые понятия привести в систему, могут ли они стать основанием «новой этики»? Видимо, да, ведь для антропоцентричного самосознания характерно удовлетворение естественных потребностей и прав человека даже путем выхода из режима самой естественности. Речь идет об удовлетворении права рожать детей, даже когда эта способность не дана природой или Богом; продолжать жить, даже когда это право забирает природа; умереть безболезненно вопреки природным процессам; изменить пол вопреки природе; уничтожить жизнь, когда она даруется природой. К какому образу человеческих отношений может привести такая этика, и в какой степени «новая система стандартов» будет действительно этикой?

Базовым для биоэтики является понятие «биологическое» в его широком смысле - как природное, естественное - это общие природные закономерности существования живого, способность живого жить, где сама жизнь представляет собой «совокупность функций, сопротивляющихся смерти». В этом плане этическое в значительной степени определяется той же природной закономерностью сохранения и развития жизни. Именно этот смысл - регуляция человеческих отношений со сверхзадачей сохранения жизни (человека, популяции, культуры) вкладывают в понятие «этическое» различные мыслители. Так, озабоченность нечеловеческим (небиологичным) поведением человека ориентирует социобиологию на биологическое изучение поведения животного с тем, чтобы найти образец биологичного поведения для человека. Известный ученый, физиолог Н. Тинберген по этому поводу пишет: «Научное понимание нашего поведения, ведущее к его контролю, - возможно наиболее необходимая задача, стоящая перед человечеством сегодня. В нашем поведении имеются такие силы, которые начинают создавать опасность для выживания вида, и что еще хуже, для всей жизни на Земле» [32]. В этом смысле биоэтика возникает уже из потребности защитить природу от «подавляющей сверх мощи» культуры в лице ее крайних антропоцентрических форм. Речь идет о защите не только от биомедицинских технологий. «Опасна не техника сама по себе, - полагал М. Хайдеггер. - Подлинная угроза уже подступила к человеку в самом его существе» [7; 14]. Это угроза от нас самих, от свободы своего правосознания, от своей «бездомности», от забвения своей подлинной естественности. Драматизм нынешнего состояния человека - в реальности двух не всегда совпадающих векторов: быть творцом и хранить свое естество. Медицина, как никакая другая область современного знания и практики, эту драму обостряет. Современная медицина вышла на принципиально новый технический, технологический и познавательный уровень. Она обрела возможности, о которых столетие назад не мечтали даже фантасты. В ее ведении оказались способности, функции, считавшиеся ранее естественными и даже священными. Медицина из тихого ремесла врачевания вдруг превратилась в мощную индустрию управления жизнью, что привело к глубоким противоречиям. Традиционные варианты медицинской этики оказались неспособными предложить новые моральные принципы, осмыслить складывающуюся систему ценностей в рамках профессии. Из этого противоречия в 60-е годы XX века и вырастает биоэтика. Ее основная задача, - реконструируя морально-мировоззренческие и культурно-исторические формы отношения к жизни и смерти, стать работающим средством разрешения реальных драматических ситуаций. Биоэтика пытается разобраться и понять пределы допустимого вторжения в основы бытия человека. По своему составу эта дисциплина охватывает ряд традиционных проблем медицинской этики. В то же время она значительно расширяет поле уже сложившейся медико-этической проблематики. 


\section{Понятие и виды медико-биологических исследований}

Современная медицина немыслима без активных научных экспериментов и исследований. Новые лекарственные средства и биодобавки, способы обследования, методы лечения должны пройти тщательную апробацию. В связи с этим возникает ряд важнейших этических проблем, главная из которых, пожалуй, как совместить научные интересы и пользу для конкретного испытуемого. Несомненно, эта проблема должна решаться, исходя из кантовского принципа: человек не средство, а цель. Врач-экспериментатор, проводящий исследование, обязан руководствоваться приоритетом блага пациента над общественной пользой и научными интересами [3; 4].

Этическая основа научных исследований сформулирована в Нюренбергском кодексе и Хельсинкской декларации ВМА. Задачи эксперимента или исследования, его план, методы, потенциальные польза и вред, вероятные осложнения должны быть четко сформулированы и представлены на рассмотрение этическому комитету (комиссии или ученому совету). Любые биомедицинские исследования должны проводиться квалифицированными в научном плане специалистами. Кроме того, испытатели должны застраховать свою ответственность на случай причинения неумышленного вреда здоровью испытуемых.

Исследования на людях делятся на два вида: медико-биологические исследования (неклинические) и клинические исследования. Медико-биологические исследования изучают реакцию, изменение состояния организма здоровых людей при воздействии определенных внешних факторов. Такие исследования дополняют и совершенствуют научные данные, но к лечению болезней прямого отношения не имеют. Клинические исследования проводятся в процессе лечения заболеваний. Эти исследования проходят по четким правилам, исключающим искажающие результат моменты. Чтобы определить эффективность медицинского воздействия, необходимы опытная и контрольная группы, количество испытуемых в каждой группе должно быть не менее 100, чтобы выявить ясные аналогии, группы должны быть примерно одинаковы по возрасту, полу, степени тяжести заболевания. Всякое исследование этично, когда оно осмысленно, хорошо организовано. Существует специфическая группа людей, которых считают «ранимыми». «Ранимыми» принято называть, прежде всего, детей, субъектов с психическими расстройствами, беременных женщин, военных, студентов-медиков, заключенных. Эти группы «ранимы» потому, что они по разным причинам не вполне свободны от принуждения экспериментатора, начальства или своего положения. Возможен риск нанесения вреда и злоупотреблений. Во многих странах испытания на беременных женщинах, плодах, новорожденных и заключенных официально запрещены. Но в крайних случаях, если исследование необходимо, поможет решить проблему данной группы и данного пациента, то его проведение может быть специально рассмотрено этическим комитетом.

Испытания и эксперименты начинаются при условии полного и доступного информирования пациента и получении его явного согласия, выраженного письменно. Исследователь должен гарантировать право пациента на отказ от продолжения исследования на любом этапе и по любым мотивам. Испытуемый может почувствовать не только физическую боль, но и эмоциональный дискомфорт, страх, предубеждение. Если испытание наносит ущерб здоровью или опасно для жизни пациента, оно должно быть немедленно прервано. Настаивание на его продолжении принесет скорее вред и исказит результаты исследований. В том случае, если пациент не может дать осознанное согласие на участие в исследовании, оно может быть получено в письменной форме от родителей, опекуна или другого законного представителя - юридически ответственного лица. Подобные исследования могут проводиться только в интересах самого пациента, ради спасения его жизни, восстановления или поддержания его здоровья. Биомедицинские исследования на людях могут проводиться врачами в следующих случаях: - если они служат улучшению здоровья пациентов, участвующих в эксперименте; - если они вносят существенный вклад в медицинскую науку и практику; - если результаты предшествующих исследований и данные научной литературы не свидетельствуют о риске развития осложнений.

\section{Эксперименты на человеке и их этические последствия}

В медицинской биологии больше, чем в других областях, невозможно проводить фундаментальные научные исследования и применять их результаты в терапии без постановки экспериментов на человеке, получивших название "клинических исследований" или "опытов на человеке". Такими необходимыми исследованиями занимались Эдвард Дженнер и Луи Пастер. 
Однако при том, что проведение таких клинических опытов является необходимым на заключительном этапе конкретного исследования, их проведение является небезопасным и не проходит бесследно для тех лиц, которые служат материалом для таких опытов.

С другой стороны, проблема состоит в том, чтобы снизить степень риска пропорционально цели и ожидаемым результатам конкретного исследования. Не упоминая повторно о нацистских врачах, осужденных на Нюрнбергском процессе, отмечу достоверность того факта, что некоторые исследователи, не имевшие нравственных принципов, и руководствовавшиеся своими личными интересами, безо всяких угрызений совести игнорировали этические нормы постановки экспериментов на человеке - если у них была уверенность в том, что их действия останутся безнаказанными. Многим известны позорные эксперименты в Государственной больнице Уиллоубрук, Нью Йорк, и Еврейской больнице для страдающих хроническими заболеваниями в Бруклине.

Широко известным является и тот факт, что фармацевтические компании часто ставят свои эксперименты в других странах, пользуясь тем, что законодательство этих других стран не запрещает постановку тех экспериментов, которые запрещены их собственным законодательством. Экспериментальная апробация вакцин "Антибэби" на людях проводилась в Индии, так как проводить ее в США не представлялось возможным.

Организация подобных мероприятий огласке, естественно, не подлежит. Когда в 1972 году выяснилось, что в Таскиги (США) на протяжении сорока лет ставились опыты на чернокожих американцах, больных сифилисом, без их осознанного согласия, пресса подняла скандал, хотя было уже поздно. Эксперимент состоял в том, что некоторым давали плацебо, не проводя никакого лечения для того, чтобы проследить за естественным развитием заболевания. Необходимость проведения опытов на людях очевидна, и в нравственном отношении является приемлемой при условии, что человек, подлежащий такому эксперименту в лечебных целях, дал на его проведение свое согласие в условиях совершенно свободного волеизъявления, и был полностью ознакомлен с планом и методикой его проведения, а также осведомлен о том риске, которым чреват этот эксперимент.

Этические проблемы возникают, когда не соблюдаются критерии получения осознанного согласия: например, когда на детях, особенно на детях с физическими недостатками, ставят клинические эксперименты без согласия их родителей или, когда клинические опыты ставятся на больных с психическими расстройствами и душевнобольных без их предварительного осведомления.

Ученые восприняли этот принцип не без сопротивления. В спорах в качестве довода они говорили, что по методическим соображениям для гарантии объективности результатов необходимы именно исследования на "вдвойне неосведомленных". Они также говорили, что на результаты оказывает влияние предубеждение, особенно в случае добровольцев (например, тюремные заключенные в США добровольно пошли на эксперимент для того, чтобы им улучшили условия содержания в местах лишения свободы). Тем не менее эксперимент в медицине становится все более смелым и требовательным, проводится на грани нравственности.

Большое количество провоцированных абортов здоровых зародышей, которые делаются сегодня по всему миру, также навело ученых на мысль использовать ткани и органы таких зародышей. Ткани человеческого зародыша можно использовать в терапии - например, для лечения некоторых типов иммунодефицита или болезни Паркинсона. С этической точки зрения это было бы приемлемым, если бы зародыш умер до использования, и если бы не существовало связи между спросом на аборты и просьбами о получении зародышевых тканей. Но в реальной жизни трудно избежать этой связи, или помешать бессовестным ученым способствовать росту числа абортов для получения свежих тканей от живых зародышей.

Как бы ни были остры материальные (физические, телесные) аспекты биоэтики, конечно, наиболее актуальными с течением времени станут проблемы модификации психики, социального поведения и вообще - сознания. Эта проблема тесно соприкасается с хорошо всем известным вопросом создания искусственного интеллекта, который мы, однако, рассмотрим отдельно, остановившись конкретно на вопросах модификации уже существующего человеческого сознания.

"Человека следует уважать в себе и в других..." - это моральное обязательство, сформулированное Эммануилом Кантом, носит абсолютный характер, и исключений из него не должно быть. Из него следует правило, состоящее в том, что "проводить на человеке какие- 
либо эксперименты можно лишь при условии полной осведомленности человека об эксперименте и при наличии его (или ее) согласия на эксперимент, полученного в условиях свободного волеизъявления" (Нюрнбергская Декларация, 1974 год) [17].

Выводы. Данная статья является одним из компонентов научных исследований автора по теоретической и практической основе исламской биоэтики. Методологическую основу статьи составляют научные труды местных и зарубежных специалистов в области биоэтики и биомедицины. Основные выводы заключаются в нижеследующем:

1. Традиционным методологическим средством для ознакомления с научно-общественнополитической и моральной сущностью биоэтики в современном мире является экскурс в историю возникновения и этапы развития предмета. Интерес к биоэтике, прежде всего, показатель глобального общественного внимания к правам человека, использования новых технологий и медицинских опытов над людьми, которые в свою очередь создают серьезные правовые и моральные проблемы в обществе. Сегодня существует необходимость изучения теоретических и исторических аспектов для исследования и классификации данной проблематики.

2. Как исследователь данной тематики с точки зрения мусульманских ученых, занимающихся биоэтикой позиция автора такова, что мировые религии, в том числе Ислам также должны внести свой вклад в установление истинных человеческих отношений с природой, и что суть религии заключается именно в разумном вмешательстве человека в окружающую среду и охране божественного порядка, установленного Всемогущим. Необходимо наряду с западными учеными, перенять здоровые и разумные ценности, полученные на основе научных достижений и в то же время сохранить наиболее важные ценности религии, в особенности священную человеческую жизнь.

\section{ЛИТЕРАТУРА}

1. Алиева М.А. Эвтаназия и проблема гуманности в медицине // Автореф. дис. кандидата философских наук. Баку-2005.

2. Аппельбаум П.С. Упущенные возможности: дееспособность и согласие при проведении исследований в психиатрии // Обзор современной психиатрии. - 1999.- Вып.

3. Асеева И.А., Никитин В.Е. Биомедицинская этика. Учебное пособие для медицинских университетов. - Курск: КГМУ, 2002. - 96 с.4.

4. Берри К. Взаимоотношения врача и пациента // Материалы Первого Украинско-британского симпозиума по биоэтике (г.Киев, 25-29 сентября 2000 г.). - К.: Киевская медицинская академия им. П.Л. Шупика, Киевский исследовательский центр "РЕАЛ".

5. Биоэтика: проблемы и перспективы / Сб. статей в журнале «Вопросы философии» - № 3 / 1994.

6. Биоэтика на рубеже тысячелетий / Материалы 5-го Всемирного Конгресса по биоэтике (Лондон, 2000). Журнал «Медицинское право и этика», № 2, 2001.

7. Бонни Штайнбок. Оксфордский учебник по биоэтике. (Bonnie Steinbock. The Oxford Handbook of Bioethics). Oxford Univ. Press. 2007.

8. Буддизм и биоэтика. (Проект: образование) Рос. Комитет по биоэтике при UNESCO/ 16.12.2009.

9. Воробьева Л.А. Этические проблемы эвтаназии // Сайт «Разум или вера» (Рос. Гуманистическое общество) 14.04.2007. www.atheismru.narod.ru

10. Гиги Альбер. Иудаизм и биоэтика // (Проект: образование) Рос. Комитет по биоэтике при UNESCO/ 16.12.2009.

11. Гуревич К.Г., Тищенко П.Д., Фабрикант Е.Г., Юдин Б.Г. Этические проблемы оказания медицинской помощи в чрезвычайных ситуациях. Изд. Московского Гуманитарного университета. М - 2007

12. Дайри Ахмед. Новая эра в биомедицине: какова позиция мусульман? // Сайт: www.islamonline.net

13. Джавадлы Гамар. Ислам и биоэтика (на азерб. языке) // Баку-2017.

14. Епископ Тихвинский Константин (Горянов). Библейская антропология и медицина // Церковнообщественный совет по биомедицинской этике. 02.02.2009.

15. Зильбер А.П. Этика и закон в медицине критических состояний // Этюды критической медицины. Петрозаводск, 1998. - Т. 4.

16. Иванюшкин А.Я. Биоэтика и психиатрия // Вопросы философии. - 1994.- №3

17. Кодекс медицинской деонтологии. - К., Сфера. - 1998.

18. Колланж Жан-Франсуа. Биоэтика и протестантизм // (Проект: образование) Рос. Комитет по биоэтике при UNESCO 16.12.2009

19. Кондратьев Ф.В. Православно-этические аспекты эвтаназии // Крымский клуб биоэтики и экологии. Сайт: bioeticsclub.narod.ru 
20. Кулиниченко В.Л. Современная медицина: трансформация парадигм теории и практики (Философско-методологический анализ). - К.: Центр практической философии. 2001

21. Мамедов В., Мамедов Р., Мустафаева А. Религиозные учения и морально-правовые критерии биоэтики //29.11.2011. www.ihr-az.org

22. Мухамедова 3.М. Исламская биоэтика в историческом аспекте// Сайт Ташкентской Медицинской Академии: www.rpam.uzsci.net

23. Основы социальной концепции Русской Православной Церкви. Изд. Московской Патриархии, 2000.

24. Отчет Рос. Ком. По биоэтике при Комиссии РФ по делам ЮНЕСКО за 2007 г. Сайт: www.kolesnikov-science.ru

25. Петров В.И., Седова Н.Н. Практическая биоэтика: этические комитеты в России. М., "Триумф", 2002.

26. Права человека и профессиональная ответственность врача в документах международных организаций. - К: Ассоциация психиатров Украины, 1996.

27. Принципы биоэтики // Биоэтика: принципы, правила, проблемы / Под ред. Юдина Б.Г. - М.: Эдиториал УРСС, 1988.

28. Проект Всеобщей декларации о биоэтике и правах человека (от 19.10.2005, рассмотренного на 33 сессии Всемирной конференции при UNESCO) // Официальный сайт министерства здравоохранения Республики Узбекистан: www.mzr.gov.uz

29. Сгречча Э., Тамбоне В. Биоэтика. Учебник. Пер. с итал. Библейско-богословский институт св.Апостола Андрея. Москва-2002.

30. Сгречча Э. Католическая церковь и профессия врача // (Проект: образование) Рос. Комитет по биоэтике при UNESCO.16.12.2009

31. Силуянова И. Биоэтика и феномен преступной государственности // Портал Фонда имени Питирима Сорокина: www.sorokinfond.ru

32. Судо Ж. История биоэтики, дискуссии, этическая ориентация // Сайт Казанского Государственного Университета-2008.

33. Тихоненко В.А. Биоэтика: проблемы, трудности, перспективы // Вопросы философии. - 1992.- № 10.

34. Точка зрения основных мировых религий на решения, касающиеся окончания жизни в отделении интенсивной терапии // Пер. с англ. Intensive Care Med (2008)

35. Требования биоэтики: Медицина между надеждой и опасениями / Сб.ст. под ред. Ф. Бриле-Виньо. Пер. с фр. К.: Сфера, 1999.

36. Факхер Бен Хамида. Мусульманская мораль, медицина и биотехнологии // Сайт Российского Комитета по биоэтике при UNESCO. 2009.

37. Холлоуелл, Келли. Клонирование и проблемы начала жизни. Пер. с англ. Христианский научноапологетический Центр, 1999. Симферополь. Буклет № 53

38. Холлоуелл, Келли. Десять «нет» исследованию эмбриональных клеток. Пер. с англ. Христианский научно-апологетический Центр, 2002. Симферополь. Буклет № 88

39. Этика геномики // Материалы конференции «Геном человека-1999» Журнал «Человек» - № 4-5, 1999 г.

40. Deep Ecology for the $21^{\text {st }}$ century // Ed. G. Sessions. Boston-London: Shambhala, 1995.

41. Kirkpatrick S. The Green Revolution // the American Enviromental Movement (1962-1992). New-York: Hill and Wang, 1993.

42. Radical environmentalism. Philosophy and Tactics // Ed. P. List. Belmont, California: Wardsworth Publishing Company, 1993.

43. Сайт www.bioetica.com.ua - Проблемы биоэтики начала XXI века 02/07.2012 